\title{
CFD SIMULATION OF ELECTROSTATIC PRECIPITATOR APPLICABLE FOR CLEAN COMBUSTION DEVICES FOR PRODUCER GAS APPLICATION
}

\author{
Prema V ${ }^{1}$, N K S Rajan ${ }^{2}$ \\ ${ }^{1}$ Assistant Professor, Department of E\&EE, SVCE, Bengaluru-57 \\ prema.smile09@gmail.com \\ ${ }^{2}$ Chief Research Scientist, C G P L, Department of Aerospace Engineering, IISc, Bangalore-12 \\ nksn@cgpl.iisc.ernet.in
}

\begin{abstract}
Electrostatic precipitators (ESPS) are well known particle separation devices used widely in several industries. It is found that applications of ESPs for gasification based power plants are not reported and there is no clarity on its performance in this environment. The gas output from the biomass gasifiers contains particulates, dust \& tar (P\&T) at a fairly low concentration levels of the order of a few PPM and still can be objectionable to applications and devices where the gas is used over a period of time. The current practice of having finer fabric filters work with a demand for higher O\&M operations. In this context it is essential to bring the P\&T to as lower level as possible so that the equipments using this in the downstream do not get affected.
\end{abstract}

Keywords: Electrostatic Precipitators, Particulates, Dust \& Tar, Gasification, Lower Level

\section{INTRODUCTION}

Biomass gasification technologies have been developed and are in use commercially for since a few decades for production of liquid and gaseous fuels. Biomass gasification is a thermo-chemical process that converts bio-residues into gaseous components into a mixture of combustible gases composed of hydrogen and carbon monoxide, small fraction of methane and other inert gases and is called in general as producer gas. Gasification also is known to generate and carry through some quantities of undesirable materials like tar, particulates, carbon and ash that could if not removed from the producer gas lead to offer constraints in its use in some devices or allow for a clean combustion limiting its applications including high efficiency power generation, domestic and industrial utilities.

A number of experiments were conducted to study the collection behavior of the ESP. The other important factor of the performance of ESPs was recognized to be having flow uniformity throughout the ESP device to see that the residence time for the gases are at their best. A simpler construction revealed un-uniform performance of the electrodes within the device, indicating the flow distribution playing a significant role.

\section{CFD SIMULATION OF ESP}

ESP geometry is modeled using Ansys 12 tools. The CFD package is subdivided into, pre-processor, solver and postprocessor.

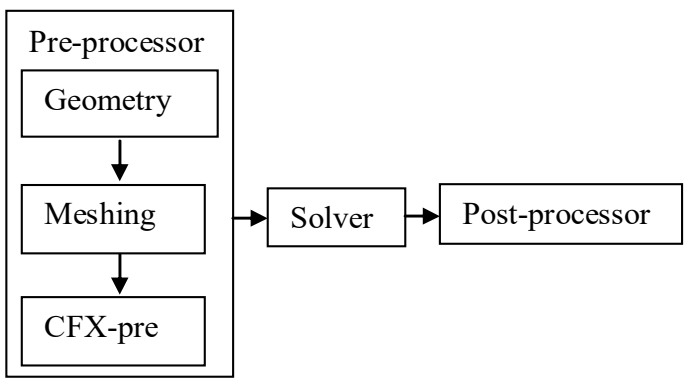

Figure 1: steps involved in the CFX

\section{A. Pre-Processor}

Geometry: Computational fluid dynamics geometry formation and meshing functions add on to ANSYS CFX and contains required tools to modify an attached or imported model to suit the demands of a desired simulation.

Meshing: Important boundary layer details is accurately captured by CFX-mesh.

CFX-Pre: CFX-Pre can read one or more meshes from a various sources. Once meshes have been loaded, the user also has significantly greater flexibility in assigning meshes to domains.

\section{B. Solver}

1. CFX's advanced Computational fluid dynamics solver technology, which uses coupled multigrid and advanced numeric's to deliver and accurate answers.

2. The broad range of physical models available to solve specific application. 
3. The flexibility of CFX, which makes the solver easy to customize and integrate within engineering environment

\section{Post-Processor}

CFX post provides adjustable and exact quantitative postprocessing of CFX results. It enables the full power of the CFX execution language within the postprocessor, and it continues with a range of post-processing distinct functions such as exact mass flow rate, area, length and volume-based integrals and averages of any quantity. Definitions can also be used to derive advanced variables for the presentation of user specified quantities.

In the ESP model following parts were created

1. Gas Inlet \& Gas Outlet

2. Inlet duct \& Outlet duct

3. Tubes

4. Flow separators

5. Baffle plates

6. Curves

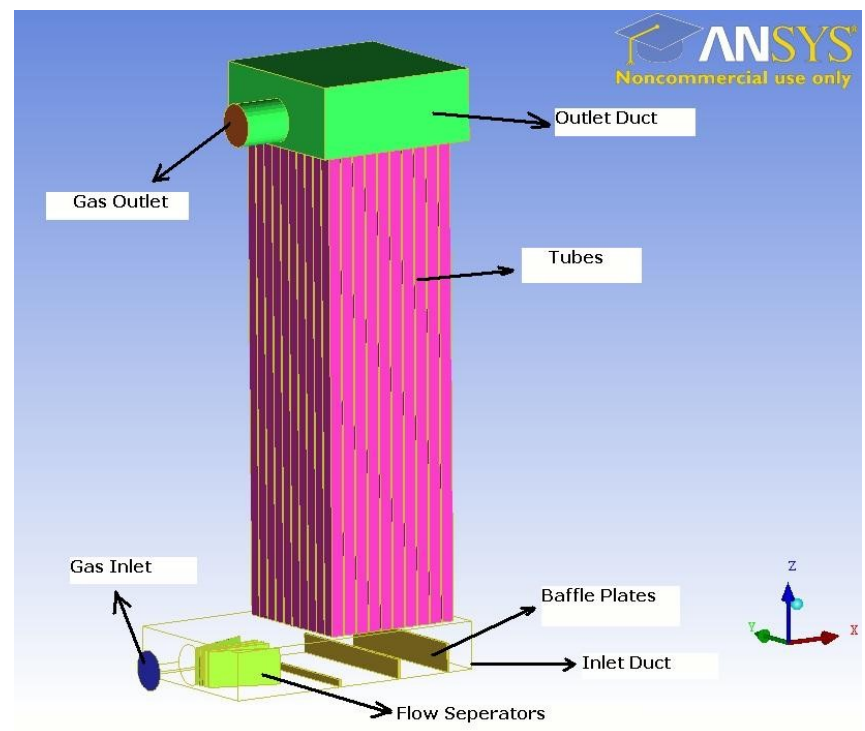

Figure 2: Model of ESP in ICEM CFD

\section{PRE-PROCESSING OF ESP:}

This stage of CFD process involved meshing, solver setup and applying the boundary conditions. All the above 3 sub stages of pre-processing are explained as sub-articles as follows.

\section{A. Meshing}

Due to complexity of the geometry, unstructured mesh was considered for meshing. The following mesh parameters were considered for meshing

1. Scale factor $=3$

2. Surface mesh size $=3$

3. Curves Mesh size $=2$

4. Total no. of elements generated after meshing $=84$ Lakhs A very fine mesh of the model was obtained.

\section{Mesh Report Generated by Ansys}

Table 1 Mesh Information

\begin{tabular}{|l|l|l|}
\hline Domain & Nodes & Elements \\
\hline Default domain & 1710047 & 8452737 \\
\hline
\end{tabular}

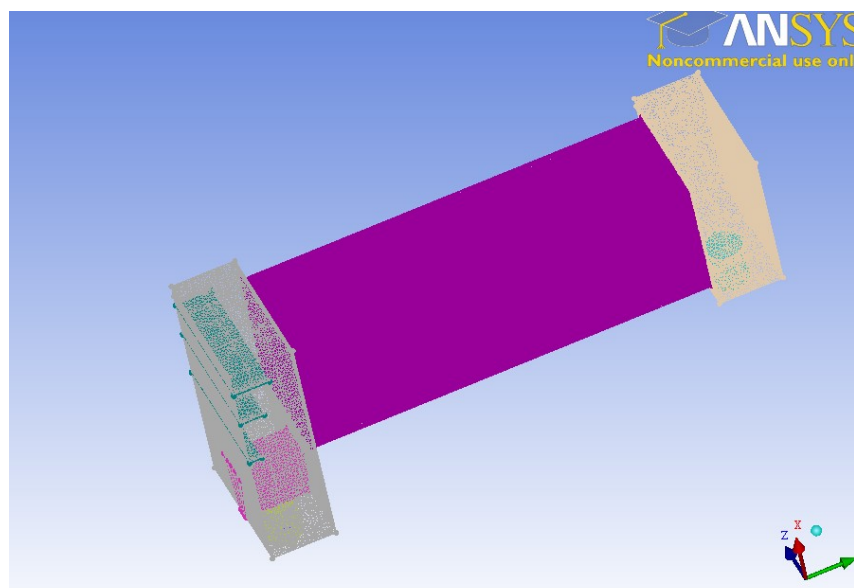

Figure 3: Meshed model of ESP in ICEM CFD

\section{B. Solver setup}

After meshing, the type of solver was selected for further numerical calculations. The following solvers were considered

\section{$\checkmark \quad$ Output Solver - Ansys CFX \\ $\checkmark$ Common Structural Solver - Ansys}

The solver file was saved for specifying the boundary conditions in CFX-Pre

Table 2: Boundary Conditions

\begin{tabular}{|l|l|l|}
\hline Domain & \multicolumn{2}{|l|}{ Boundaries } \\
\hline \multirow{5}{*}{ Default Domain } & Boundary_Gas inlet & Inlet \\
\cline { 2 - 3 } & Type & Gas Inlet \\
\cline { 2 - 3 } & Location & Normal to boundary condition \\
\cline { 2 - 3 } & Settings & Subsonic \\
\cline { 2 - 3 } & Direction of flow & Mass flow rate \\
\cline { 2 - 3 } & Flow region & \\
\cline { 2 - 3 } & Momentum \& Mass & Medium intensity and eddy viscosity ratio \\
\hline
\end{tabular}




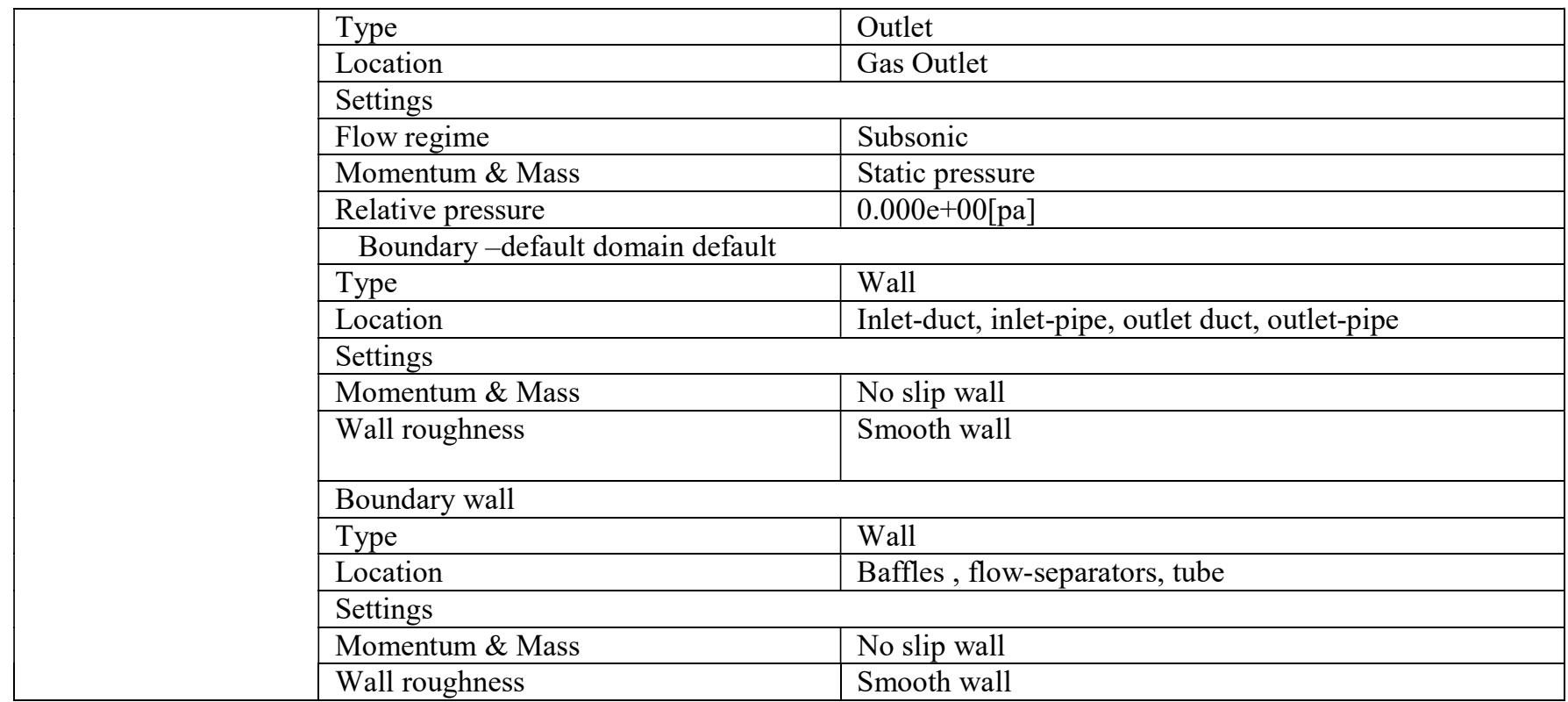

\section{POST PROCESSING}

The converged solution file was then opened using Ansys CFX-Post software. Gas flow is achieved through the ESP from velocity plots.

From the below figure 4, without Baffle plates and flow separators the gas flow is not taking place in all the tubes uniformly throughout the length of ESP.

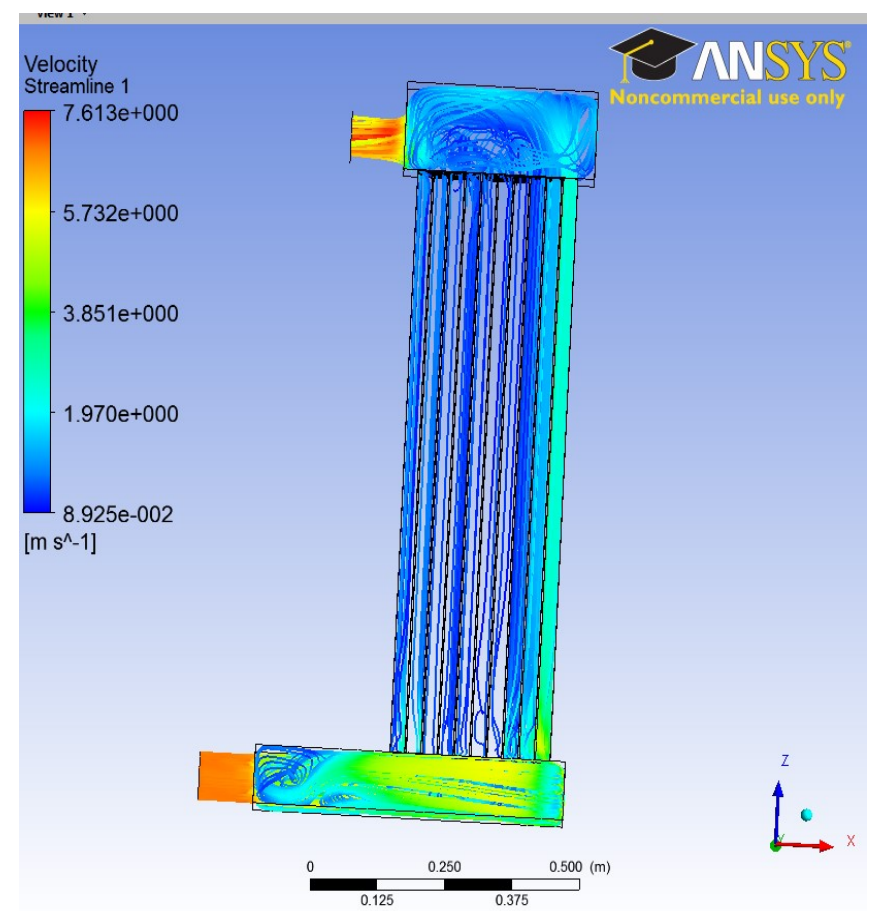

Figure 4: Streamline flow in ESP without baffle \& flow separators

From the below figure 5, with Baffle plates helped in bringing uniform the gas flow in all the tubes throughout the length of ESP.

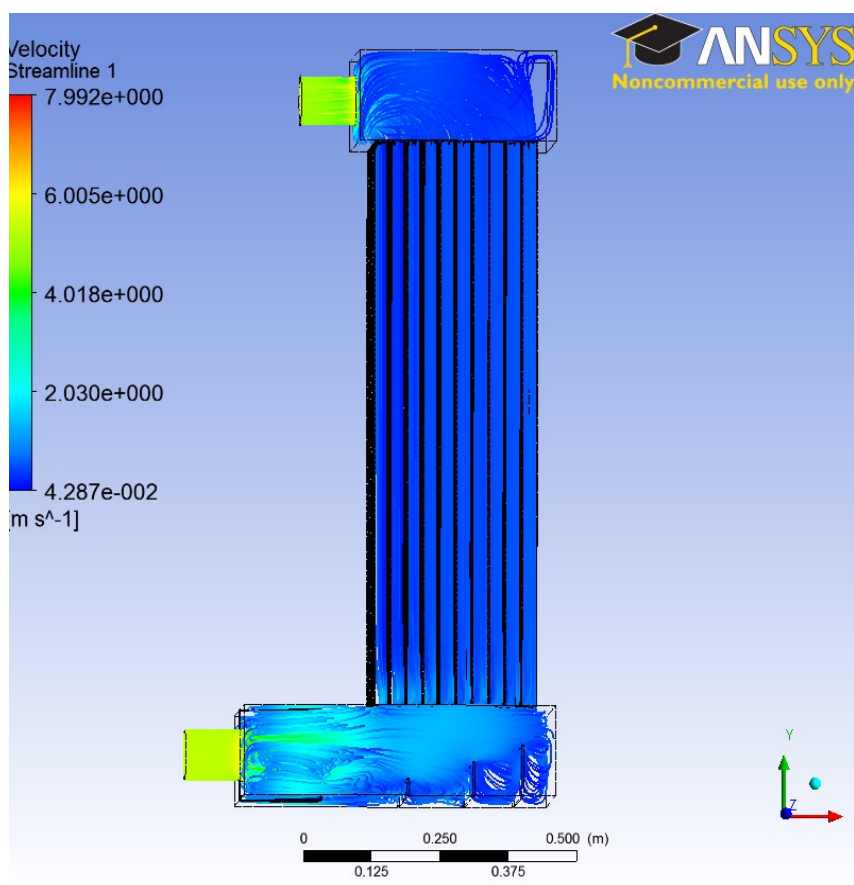

Figure 5: Streamline flow in ESP

A set of CFD simulations that lets to examine the uniformity of the flow structure and consequent geometrical fine-tuning for the flow paths was made with the required parameters.

\section{CONCLUSION}

Computational fluid dynamics gives an insight into flow structure that are problematic, costly or impossible to study using conventional (experimental) techniques. Flow simulation of Electrostatic precipitator has been done using the CFD and it can be seen that the flow has maintained uniform across the tube bundle. The CFD tool reduced both time and cost parameters as there was no need to physically fabricate baffle plates of different sizes and at different locations on the plate. 


\section{REFERENCES}

[1]. S.V.B Van paasen1, tar removal with a wet electrostatic precipitator (ESP).

[2]. Zhenyu Du "A Numerical Simulation for Predicting Influence of Flow Pattern in Electrostatic Precipitations on Dust Loading Centers", Bioinformatics and Biomedical Engineering , 2009

[3]. G. SKODRAS, particulate removal via electrostatic precipitators-CFD simulation

[4]. A.Jaworek, A. Krupa, T. Czech, Modern electrostatic devices and methods for exhaust gas cleaning: a brief review, J. Electrostat. 65 (2007).

[5]. J.D. Bapat, Application of ESP for gas cleaning in cement industry with reference to India, Journal of Hazardous Materials B81 (2001).

[6]. C. A.J.Fletcher, Computational techniques for fluid dynamics-1, fundamental and general techniques, $2^{\text {nd }}$ edition, 1990.

[7]. C. Mao, M. Bai, C. Yi, X. Bsi, "Experimental study of transportation characteristic of charged particle in electrostatic precipitation," High Voltage Engineering, 2007.

[8]. F. Wang, "Computational fluid dynamics analysis-CFD Software Theory and Application." Beijing, Tsinghua University Press, 2004.

[9]. H. Zhao, C. Zheng, "Numerical Simulation of Singlestage Electrostatic Precipitator for Collecting Fly Ashes," 2007.

[10].S.H. Kim, K.W. Lee, Experimental study of electrostatic precipitator performance and comparison with existing theoretical prediction models, Journal of Electrostatics 48 (1999).

[11].Chang, J.S.; Dekowski, J.; Podlinski, J.; Brocilo, D.; Urashima, K.; Mizeraczyk, J. "Electrohydrodynamic gas flow regime map in a wire-plate electrostatic precipitator under positive coronas", Electrical Insulation and Dielectric Phenomena, 2005.

[12].J. Podlinski, A. Niewulis, J. Mizeraczyk, P. Atten, ESP performance for various dust densities, J. Electrostat. $66(2008)$ 